EXTENDED REPORT

\title{
Galectin-3 surface expression on human adult chondrocytes: a potential substrate for collagenase-3
}

\author{
M Guévremont, J Martel-Pelletier, C Boileau, F-T Liu, M Richard, J-C Fernandes, J-P Pelletier, \\ P Reboul
}

See end of article for authors' affiliations

Correspondence to: Dr P Reboul, Osteoarthritis Research Unit, CR-CHUM, Y2604, 1560 Sherbrooke Street East, Montreal, Quebec, Canada H2L 4M1; pascal.reboul@ umontreal.ca

Accepted 17 August 2003
Background: Galectin-3 is a lectin detected in mature and early hypertrophic chondrocytes; osteoarthritic (OA) chondrocytes can re-express hypertrophic markers.

Objective: To investigate the synthesis and subcellular localisation of galectin-3 in adult chondrocytes as well as the possibility of cleavage of galectin- 3 by collagenase- 1 and -3 .

Methods: Galectin-3 was assessed by immunohistochemistry and real time polymerase chain reaction (PCR) in normal and OA cartilage. Its localisation was investigated by subcellular fractionation, immunocytology, and flow cytometry. Proteolysis of galectin- 3 by collagenase- 1 and -3 was determined by in vitro assay.

Results: Galectin-3 expression was increased 2.4-fold as measured by reverse transcriptase (RT)-PCR $(p<0.05, n=5)$ and threefold by immunohistochemistry $(p<0.003 n=6)$ in OA cartilage compared with normal cartilage. In adult chondrocytes, galectin-3 was found in the cytosol and membrane enriched fractions. Both immunocytology and flow cytometry confirmed the presence of galectin-3 at the surface of chondrocytes. A strong correlation was found between integrin- $\beta 1$ and galectin-3 expression at the surface of chondrocytes. Moreover, collagenase-3 cleaved galectin-3 with a higher activity than collagenase-1. The proteolysed sites generated were identical to those produced by gelatinases $A$ and $B$. Conclusion: Galectin-3 may play a part in OA, having two roles, one intracellular and not yet identified, and another at the cell surface, possibly related to the interaction of chondrocytes and the cartilage matrix.
A bnormality in cartilage is age related and, consequently, osteoarthritis (OA) is one of the most prevalent diseases in older people. ${ }^{12}$ OA involves both a decreased reparative process and an increased degradative phenomenon, thereby limiting the capacity for articular cartilage repair. ${ }^{3}$ The metabolic modifications of chondrocytes that occur during the onset of OA are related both to new stimuli (proinflammatory cytokines, growth factors from subchondral bone) and to changes in the cartilage extracellular matrix (ECM) composition. These metabolic modifications lead chondrocytes to re-express proteins normally produced in hypertrophic chondrocytes during bone development. Galectin-3 is one of these molecules and its expression seems to be highly regulated in this process.

Galectin-3 is an animal lectin that belongs to the galectin superfamily. Galectins, like other lectins, recognise a glycosylation structure with neither enzymatic nor immune activity. ${ }^{5}$ The galectin-3 gene, first identified as the macrophage marker 2 protein, was mapped on human chromosome 14 (14q21-22). This gene has $17 \mathrm{~kb}$ and is composed of six exons and five introns and codes for a soluble protein of $30 \mathrm{kDa}^{6}{ }^{7}$ Although first discovered in macrophages, galectin-3 has been found to be more widely distributed in tissues, which include the gut, brain, kidneys, and skeleton. ${ }^{8}$ Reported data also suggest that galectin-3, depending on its subcellular localisation, participates in a variety of processes such as RNA splicing, ${ }^{9}$ differentiation, ${ }^{10}$ apoptosis, ${ }^{11-13}$ and cell-cell or cell-matrix interactions. ${ }^{14-17}$ Among different extracellular ligands of galectin- $3,{ }^{17-20}$ fibronectin and integrins, which are increased in OA cartilage, may have a role in modifying diseased chondrocyte metabolism. ${ }^{21} 22$ In addition, galectin-3 has been identified as an advanced glycation end product receptor, ${ }^{23}$ and glycation end products are involved in OA. ${ }^{24}{ }^{25}$ Moreover, the proteolysis of galectin-3 by metalloproteinases (MMPs), such as gelatinase A (MMP2) or gelatinase B (MMP-9), can modify these interactions when galectin-3 is expressed at the cell surface. ${ }^{17} 26$

In bone development, galectin-3 is found in both osteoblasts $^{27}{ }^{28}$ and osteoclasts, ${ }^{28}$ as well as in chondrocytes. ${ }^{27}{ }^{28}$ More particularly, galectin-3 is expressed in the early hypertrophic chondrocytes of the growth plate; however, it is rarely found in the late hypertrophic chondrocytes undergoing terminal maturation in the calcified zone. ${ }^{29} \mathrm{~A}$ knockout mouse model has indicated that galectin-3 is implicated in the chondrocyte death and vascular invasion coupling process. These results suggest a role for galectin-3 as a regulator of chondrocyte survival. ${ }^{31}$

Because OA chondrocytes re-express hypertrophic genes, we first investigated the presence of galectin-3 in human normal and OA cartilage. Then, we focused on the galectin- 3 subcellular localisation in chondrocytes and more particularly at the cell surface. Moreover, we investigated the capacity of collagenase- 1 and -3 to cleave galectin-3.

\section{MATERIALS AND METHODS}

\section{Specimen selection}

Human chondrocytes from articular cartilage (femoral condyles and tibial plateaus) were obtained from 13 normal donors (mean (SD) age $63(13))$ and 15 patients with OA (aged 65 (7)) who had undergone total knee arthroplasty. All patients with OA were evaluated by a certified rheumatologist and were diagnosed as having OA based on the criteria

\footnotetext{
Abbreviations: 7-AAD, 7-aminoactinomycin D; ECM, extracellular matrix; MMP, matrix metalloproteinase; OA, osteoarthritis/ osteoarthritic; PBS, phosphate buffered saline; PCR, polymerase chain reaction; RT-PCR, reverse transcriptase-polymerase chain reaction; SDSPAGE, sodium dodecyl sulphate-polyacrylamide gel electrophoresis
} 
developed by the American College of Rheumatology Diagnostic Subcommittee for OA. ${ }^{32}$

\section{Chondrocyte culture}

Chondrocytes were released from the articular cartilage by sequential enzymatic digestion at $37^{\circ} \mathrm{C}$ as previously described $^{33}$ and cultured in Dulbecco's modified Eagle's medium (Gibco-BRL, Burlington, Ontario, Canada) supplemented with $10 \%$ heat inactivated fetal bovine serum (Gibco$\mathrm{BRL})$ and an antibiotic mixture (100 U/ml penicillin base, $100 \mu \mathrm{g} / \mathrm{ml}$ streptomycin base; Gibco-BRL) in a humidified atmosphere of $5 \% \mathrm{CO}_{2} / 95 \%$ air. First passage OA chondrocytes were used in all experiments.

\section{Immunohistochemistry detection of galectin-3}

Cartilage specimens from normal subjects and patients with $\mathrm{OA}$ were processed for immunohistochemical analysis as previously described. ${ }^{34}{ }^{35}$ Briefly, specimens were fixed in TissuFix No 2 (Laboratoires Gilles Chaput, Montreal, Quebec, Canada) for 24 hours, then embedded in paraffin. Sections $(5 \mu \mathrm{m})$ of paraffin embedded specimens were placed on Superfrost Plus slides (Fisher Scientific, Nepean, Ontario, Canada), deparaffinised in toluene, rehydrated in a graded series of ethanol, and preincubated with chondroitinase ABC (0.25 U/ml; Sigma-Aldrich, Canada) in phosphate buffered saline (PBS) pH 8.0 for 60 minutes at $37^{\circ} \mathrm{C}$. After this, the specimens were washed in PBS, then placed in $0.3 \%$ hydrogen peroxide/PBS for 15 minutes. Slides were further incubated with a blocking serum for 60 minutes, blotted, and then overlaid with a rabbit serum containing primary polyclonal antibodies against galectin-3 (Covalab, Oullins, France; dilution $1 / 2500$ ) for 18 hours at $4^{\circ} \mathrm{C}$ in a humidified chamber. Each slide was washed three times in PBS (pH 7.4) and stained using the avidin-biotin complex method (Vectastain ABC kit; DAKO Diagnostics, Canada). This method entails incubation in the presence of the biotin conjugated secondary antibody for 45 minutes at room temperature followed by the addition of the avidin-biotinperoxidase complex for 45 minutes. All incubations were carried out in a humidified chamber at room temperature and the colour developed with a 3,3'-diaminobenzidine (DAKO Diagnostics, Canada) containing hydroxide peroxide. Slides were counterstained with saffron. To determine the specificity of staining, slides were incubated with a rabbit non-immune serum (Vector Laboratories Inc, Burlingame, CA). Several sections were made from each block of cartilage and slides from each specimen were processed for immunohistochemical analysis. Each section was examined under a light microscope (Leica DMLS, Leica, Weitzlar, Germany) and photographed with CoolSnap CF and RS image software (Roper Scientific Inc. Tucson, AZ).

\section{Morphometric analysis}

The antigen in cartilage was quantified as described previously. ${ }^{34} 36$ The presence of the antigen was estimated by determining the number of chondrocytes staining positive in the entire thickness of cartilage. Cartilage was divided into three microscopic fields ( $\times 20$; Leitz Diaplan) and the results averaged. For each arthritic specimen, it was ensured before evaluation that an intact cartilage surface could be detected and used as a marker for validation of morphometric analysis. The total number of chondrocytes and the number of chondrocytes staining positive for the specific antigen were determined. The final results were expressed as the percentage of chondrocytes staining positive for the antigen (cell score), with the maximum score being 100\%. Values are expressed as median and range. Statistical analysis was performed using the Mann-Whitney $U$ test. Values of $\mathrm{p}<0.05$ were considered significant.

\section{Quantitative polymerase chain reaction (PCR)}

\section{RNA extraction}

Human articular cartilage was homogenised in Trizol reagent, followed by the addition of chloroform as described.$^{37}$ After being shaken and cooled at $4^{\circ} \mathrm{C}$ for 1 hour, the solution was centrifuged $\left(12000 \mathrm{~g}, 2\right.$ hours at $\left.4^{\circ} \mathrm{C}\right)$. The aqueous phase was transferred to a new tube and precipitated with one volume of isopropyl alcohol overnight at $-20^{\circ} \mathrm{C}$. After centrifugation $\left(12000 \mathrm{~g}, 30\right.$ minutes at $\left.4^{\circ} \mathrm{C}\right)$, the pellet was resuspended in QIAGEN lysis buffer from the RNeasy Plant mini-kit and extracted according to the manufacturer's protocol (QIAGEN Inc, Mississauga, ON, Canada). RNA was measured by the RiboGreen ${ }^{\circledR}$ RNA reagent (Molecular Probe, Eugene, OR).

\section{Reverse transcriptase-polymerase chain reaction (RT-PCR)}

Total RNA ( $2 \mu \mathrm{g}$ ) was used in the RT-PCR reaction. The assay was carried out in a Gene ATAQ controller (Amersham Pharmacia Biotech, Baie d'Urfé, PQ, Canada). The RNA was converted to single stranded DNA with 50 units of M-MLV reverse transcriptase (InVitrogen) in $20 \mu \mathrm{l}$ of reaction mixture containing $10 \mathrm{mM}$ Tris- $\mathrm{HCl} \mathrm{pH} \mathrm{8.3,} 50 \mathrm{mM} \mathrm{KCl}$, $5 \mathrm{mM} \mathrm{MgCl}, 1 \mathrm{mM}$ of each dNTP (Amersham Pharmacia Biotech), $2.5 \mu \mathrm{M}$ random hexamers (Amersham Pharmacia Biotech), and 20 units RNAse inhibitor. The mixture was incubated at $42^{\circ} \mathrm{C}$ for 45 minutes and at $99^{\circ} \mathrm{C}$ for 5 minutes. Real time PCR on a Gene Amp 5700 Sequence Detector System (Applied BioSystems, Foster City, CA) was performed in a total volume of $50 \mu \mathrm{l}$ in the presence of $10 \mathrm{ng}$ 18S cDNA or 100 ng galectin-3 cDNA. Water was used as a negative control. $\mathrm{MgCl}_{2}$ was added to a final concentration of $2 \mathrm{mmol} /$ l, each oligonucleotide primer added to a final concentration of $100 \mathrm{nmol} / \mathrm{l}$, and the $\mathrm{SYBR}^{\circledR}$ Green core reagents added according to the manufacturer's instructions (Applied BioSystems). To avoid sample contamination from previous amplifications, an initial step with AmpErase UNG was performed for 2 minutes at $50^{\circ} \mathrm{C}$ followed by an AmpErase inactivation $\left(10\right.$ minutes at $\left.95^{\circ} \mathrm{C}\right)$. PCR was performed with an initial step for 5 minutes at $95^{\circ} \mathrm{C}$ followed by 40 cycles of 15 seconds at $95^{\circ} \mathrm{C}$ and 1 minute at $60^{\circ} \mathrm{C}$. We verified that a single peak was obtained for each product using the Gene Amp 5700 Sequence Detector System software. PCR primers for galectin-3 were sense 5'-GGCCACTGATTGTGCCTTAT and antisense 5'-TCTTTCTTCCCTTCCCCAGT. These primers were designed using Primer3 software (http://www.genome.wi. mit.edu/cgi-bin/primer/primer3_www.cgi; accessed 10 March 2004) and produced a $224 \mathrm{bp}$ amplified fragment. Specific primers for $18 \mathrm{~S}$ were sense 5'-GAATCAGGGTTCGATTCCG and antisense 5'-CCAAGATCCAACTACGAGC, which gave a 279 bp amplified fragment. Primers were synthesised by Alpha DNA (Montreal, Quebec, PQ, Canada). Data analysis was carried out using the comparative Ct method with the Gene Amp 5700 Sequence Detector System software. The level of galectin-3 expression was normalised to $18 \mathrm{~S}$. Statistical analysis was performed using Student's $t$ test. Values of $\mathrm{p}<0.05$ were considered significant.

\section{Cell fractionation}

OA chondrocytes were recovered with a cell scraper in a hypotonic buffer (20 mM Tris $\mathrm{HCl}, 50 \mathrm{mM} \mathrm{NaCl}, \mathrm{pH}$ 7.5). Cells were submitted to a freeze-thaw cycle, sonicated at $40 \mathrm{~V}$ (Vibra cell, Sonics \& Material Inc, Danbury, CT) for 20 seconds, and then centrifuged at $200 \mathrm{~g}$. Pellets containing nuclei were saved while supernatants were centrifuged at $100000 \mathrm{~g}$. Pellets obtained after this step contained membrane enriched fractions, whereas supernatants were composed of cytosol. Pellets were then resuspended in $20 \mathrm{mM}$ Tris $\mathrm{HCl}, 50 \mathrm{mM} \mathrm{NaCl}, \mathrm{pH} 7.5$, containing $0.1 \%$ of Nonidet 
P40. Proteins of each fraction were assessed with the bicinchoninic acid method ${ }^{38}$ and analysed using western blotting with the anti-galectin-3 antibody (dilution 1/40 000) and a monoclonal anti-integrin- $\beta 1$ (Chemicon International Inc, Temecula, CA; dilution 1/5000)

\section{Immunocytology}

OA chondrocytes were seeded in eight well Lab-Tek chamber slides (Nunc, Naperville, IL) at a density of 30000 cells $/ \mathrm{cm}^{2}$. Cells were incubated overnight, washed twice in PBS, and fixed in TissuFix No 2. Immunostaining was performed and analysed with both optical and fluorescent microscopy. After fixation, slides were rinsed three times in PBS. For cell permeabilisation, some slides were incubated in PBS containing $0.3 \%$ Triton X100 for 30 minutes and then rinsed three times in PBS. After blocking in a humidified chamber with $1.5 \%$ goat serum (Vector Laboratories Inc) in PBS for 1 hour, the polyclonal anti-galectin-3 antibody was incubated over- night at a dilution of 1/10 000. Controls were performed with non-immune rabbit serum (Vector Laboratories Inc). For fluorescent microscopy, an Alexa conjugated antirabbit IgG (Molecular probes, Eugene, OR) was used at a dilution of 1/5000. Cells were examined under a Nikon Eclipse TE300 fluorescent microscope. Images were recorded with a CCD camera (Roper Scientific Inc) and Metafluor software (University Imaging Corp). Three independent experiments were performed.

\section{Flow cytometry}

Primary human OA chondrocytes were briefly trypsinised, rinsed in PBS containing $1.5 \%$ goat serum, and incubated with either the anti-galectin-3 antibody (dilution 1/100) or with the monoclonal anti-integrin- $\beta 1$ (dilution 1/250) for 1 hour. Non-immune serum was used at the same concentration and served as control. After rinsing, cells were incubated in a secondary antibody conjugated to
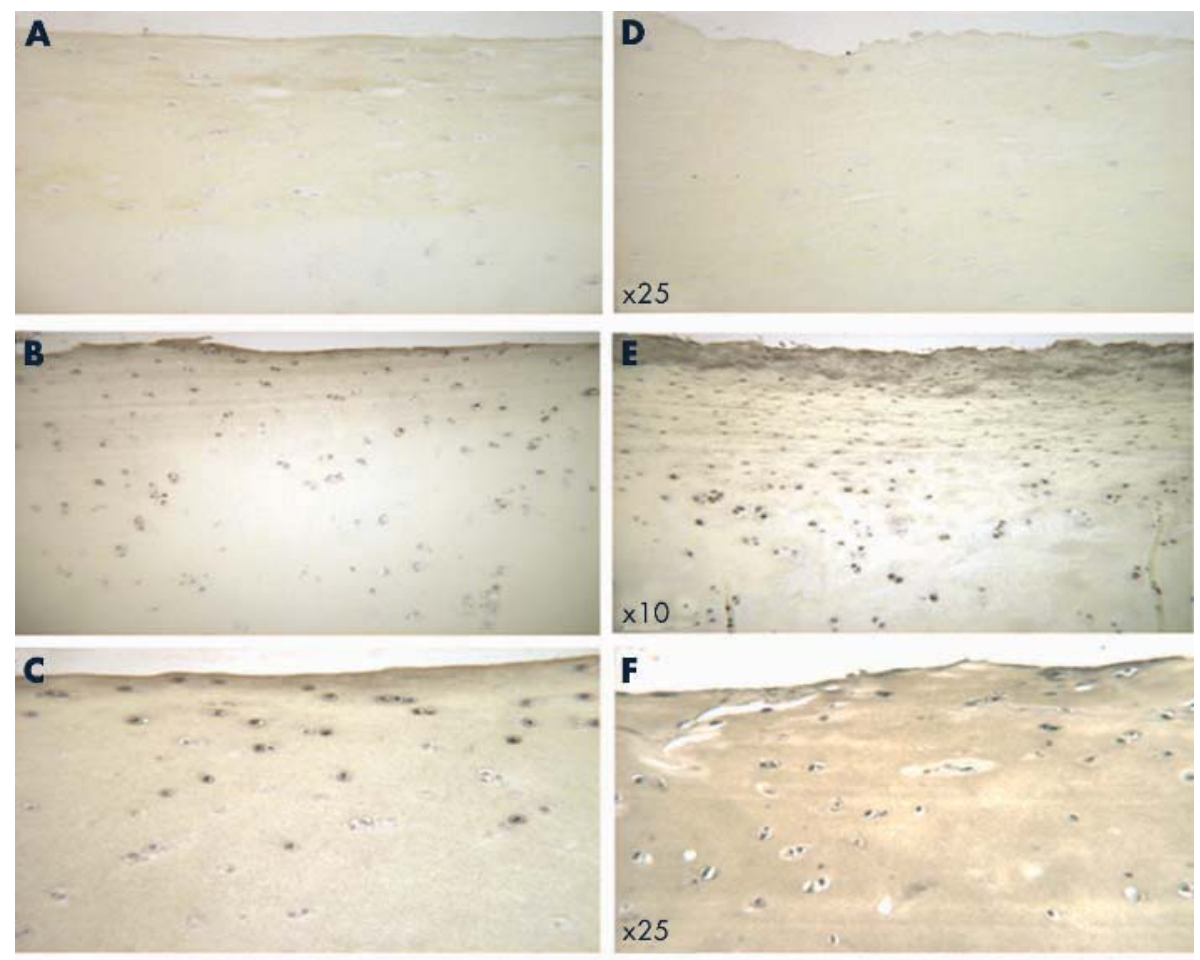

G

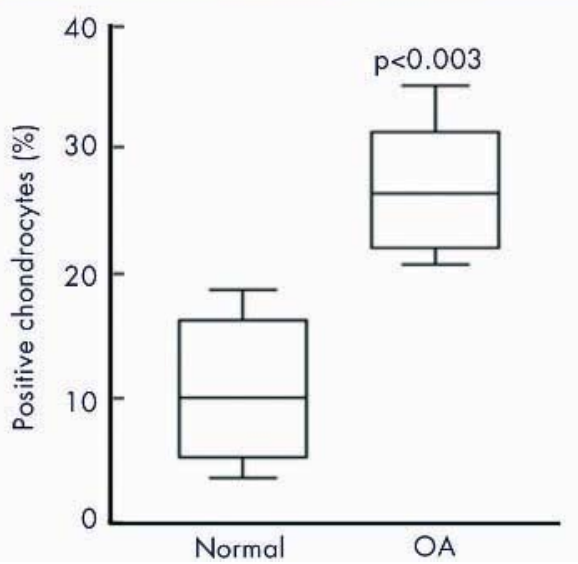

Figure 1 Representative section of cartilage, showing immunostaining for galectin-3 from normal $(A-C)$ and $O A$ cartilage (D-F). (A and D) Nonimmune serum; (B, C, E, and F) polyclonal anti-galectin-3. Original magnification $\times 25$; (G) galectin-3 levels over the entire cartilage thickness. Data are presented as box plots, where the boxes represent the first and third quartiles, the lines within the boxes represent the median, and the lines outside the boxes represent the spread of the galectin-3 cell scores outside the first and third quartiles. The $p$ value, obtained with the Mann-Whitney test, indicates the difference compared with the normal group. 
phycoerythrin (dilution 1/100; Jakson Immunoresearch Laboratories, West Grove, PA) for 30 minutes and then rinsed in PBS for 10 minutes before samples were read in a FACScan (Becton-Dickinson, Oakville, ON, Canada). A cell non-permeable stain, 7-aminoactinomycin D (7-AAD; Molecular Probes), was added 5 minutes before reading to discriminate permeabilised cells from whole cells.

\section{Proteolysis analysis of galectin-3}

Human recombinant galectin-3, generated as previously described, ${ }^{39}$ was incubated with either activated human recombinant collagenase- 1 or -3 or gelatinase $A$ at a molecular ratio of $1 / 50$ and $1 / 10$ for 30 minutes at $37^{\circ} \mathrm{C}$ in $50 \mathrm{mM}$ Tris- $\mathrm{HCl}$ buffer, $\mathrm{pH} 7.5$, containing $150 \mathrm{mM} \mathrm{NaCl}$ and $10 \mathrm{mM} \mathrm{CaCl}_{2}$. Incubation was stopped with a volume of $6 \times$ denaturing Laemmli buffer, and the entire sample was loaded on a $4-12 \%$ sodium dodecyl sulphate-polyacrylamide gel electrophoresis (SDS-PAGE) system. After migration, proteins were detected with silver nitrate staining (Bio-Rad; Mississauga, Ontario, Canada).

\section{Sequencing of galectin-3 fragments}

Recombinant galectin-3 was digested by collagenase- 3 as above. Fragments were separated by $4-12 \%$ SDS-PAGE and blotted for 1.5 hours at $180 \mathrm{~mA}$ onto a PVDF membrane using $10 \mathrm{mM}$ CAPS, pH 10.8, containing $10 \%$ methanol as a transfer buffer. Fragments were detected using Coomassie blue staining and bands were cut and analysed for amino acid sequence (Sheldon Biotechnology Centre, McGill University, Montreal, Quebec, Canada).

\section{RESULTS \\ Galectin-3 expression by human normal and $O A$ chondrocytes}

OA chondrocytes are often compared with hypertrophic-like chondrocytes owing to their ability to express several proteins also found in developing bone. For example, OA chondrocytes re-express annexins II and $\mathrm{V},{ }^{40}{ }^{41}$ collagenase- $3,{ }^{42}{ }^{43}$ osteopontin, ${ }^{44}$ and type $\mathrm{X}$ collagen. ${ }^{45}$ In this study we investigated the capacity of human normal and OA chondrocytes to synthesise galectin-3, which was previously described as expressed by hypertrophic chondrocytes during bone development. ${ }^{29}{ }^{30}$ Data obtained by immunohistochemistry showed that galectin-3 was expressed by normal (figs IB and $\mathrm{C}$ ) and $\mathrm{OA}$ cartilage (figs $\mathrm{IE}$ and $\mathrm{F}$ ). In contrast, nonimmune serum showed no signal (figs IA and D). Moreover,

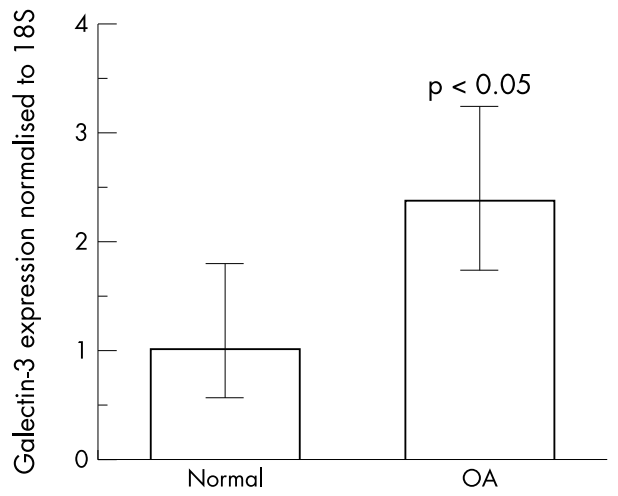

Figure 2 Expression of galectin-3 mRNA in human normal and OA cartilage was studied using real time RT-PCR as described in "Materials and methods". The PCR analysis was performed by normalising the PCR products of the galectin-3 to the $18 \mathrm{~S}$ PCR products. Bars show the mean (SD) intensity of five normal and OA specimens. The $p$ value, obtained with Student's $t$ test, indicates the difference compared with the normal group. the quantitative measurement of galectin-3 staining (fig $1 G$ ) was significantly increased in OA cartilage (median 26.5\% (range 20.8-35.2)) compared with normal cartilage (10.1\% (3.6-18.8), $\mathrm{p}<0.003, \mathrm{n}=6$ ). As illustrated in fig 2, we confirmed, using real time PCR, that galectin-3 mRNA was expressed at a higher level in OA than normal cartilage (2.4fold, $\mathrm{p}<0.05, \mathrm{n}=5$ ).

\section{Subcellular distribution of galectin-3 in OA chondrocytes}

As the function of galectin-3 depends on its subcellular localisation, we determined its localisation using a subcellular fractionation methodology. Data showed that galectin-3 was present in cytosol as well as in nuclear and membrane enriched fractions (fig 3). This result corroborated the main localisations of galectin-3 in different cell lines. ${ }^{46-50}$ However, up to now galectin-3 has never been found in the plasma membranes of chondrocytes. The quality of the membrane enriched fraction was assessed using a specific marker of plasma membrane. Integrin- $\beta 1$ was chosen because it was previously shown to be expressed at the surface of chondrocytes. ${ }^{51}{ }^{52}$ As represented in fig 3, a stronger signal was obtained with the anti-integrin- $\beta 1$, in the fraction enriched with plasma membrane, indicating that this part of the fractionation was of good quality. In contrast, some integrin- $\beta 1$ was also detected in the nuclear fraction, suggesting that non-lysed cells might contaminate this fraction. Therefore we analysed the nuclear staining in confocal microscopy by colocalising, in permeabilised cells, galectin-3 and Sytox green, a nuclear marker. No galectin-3 was found in the nuclei (data not shown, $\mathrm{n}=2$ ).

To verify the new localisation of galectin-3 at the surface of adult chondrocytes, we pursued our studies using immunocytology. Cells were either permeabilised or non-permeabilised by using or not $0.3 \%$ of Triton X100 before the incubation with the anti-galectin-3 antibody. As illustrated in Figure 4, no staining was noted with the non-immune serum (figs $4 \mathrm{~A}$ and $\mathrm{C}$ ). Furthermore, data demonstrated a weaker signal in non-permeabilised cells (fig 4B) than in permeabilised cells (figs 4D), which again suggests the
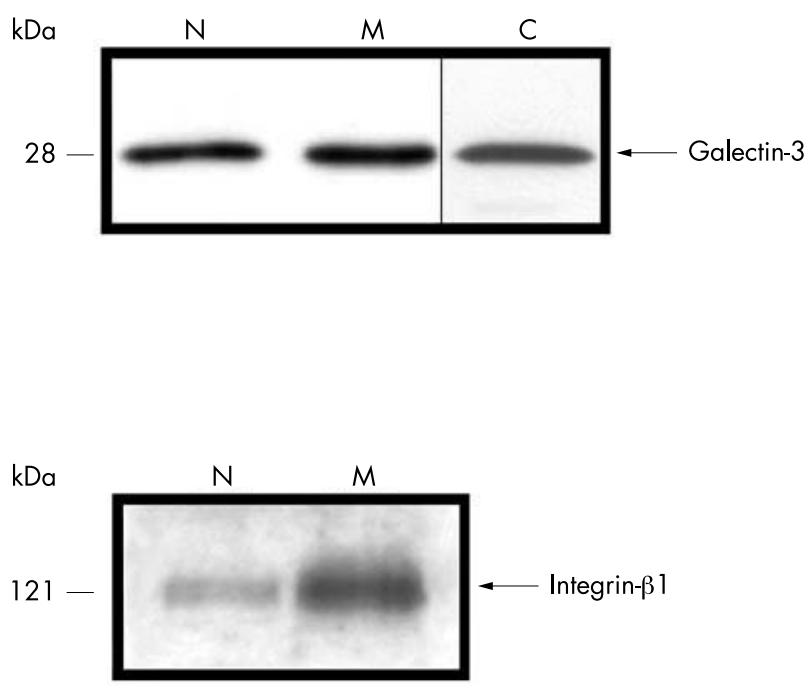

Figure 3 Subcellular OA chondrocyte fractionation was performed as described in "Materials and methods". Proteins were quantified for each fraction, $10 \mu \mathrm{g}$ were blotted, and immunodetection was performed with either a polyclonal anti-galectin- 3 or a monoclonal anti-integrin- $\beta 1$ antibody. $N$, nuclear fraction; $M$, membrane enriched fraction; $C$, cytosol. 
localisation of galectin-3 at the chondrocyte surface, confirming the results from fig 3.

To rule out definitively the possibility of membrane permeabilisation during sample preparation (as could, for example, occur in the fixative step), we decided to use flow cytometry. Indeed, this methodology allowed the sorting of non-permeabilised and permeabilised cells by using 7-AAD staining, which can penetrate the cells only when the plasma membrane is disrupted. Results showed that only $5 \%$ of total cells had a disrupted membrane at the end of incubations in the flow cytometry experiments (data not shown). Therefore, $95 \%$ of chondrocytes in these preparations were used to analyse the surface labelling. As expected, data for intact cells showed a shift of the phycoerythrin signal in the presence of the anti-galectin-3 antibody when compared with the cells treated with the non-immune serum (fig $4 \mathrm{E}$ ). This finding definitively demonstrated that galectin-3 was expressed at the surface of adult chondrocytes. Because Ochieng et al had previously demonstrated interactions between galectin-3 and integrins, ${ }^{15}$ we investigated whether these two proteins could be related in chondrocytes. Therefore, by using flow cytometry, we compared the integrin- $\beta 1$ expression with the expression of galectin-3 measured at the chondrocyte surface. A strong correlation $\left(R^{2}=0.8699, \mathrm{n}=6\right)$ was seen regardless of whether samples came from normal subjects or patients with OA (fig 5).

\section{Proteolytic activity of collagenase-3 on galectin-3}

It has been previously shown that when galectin-3 is expressed at the cell surface its $\mathrm{N}$-terminal domain is a
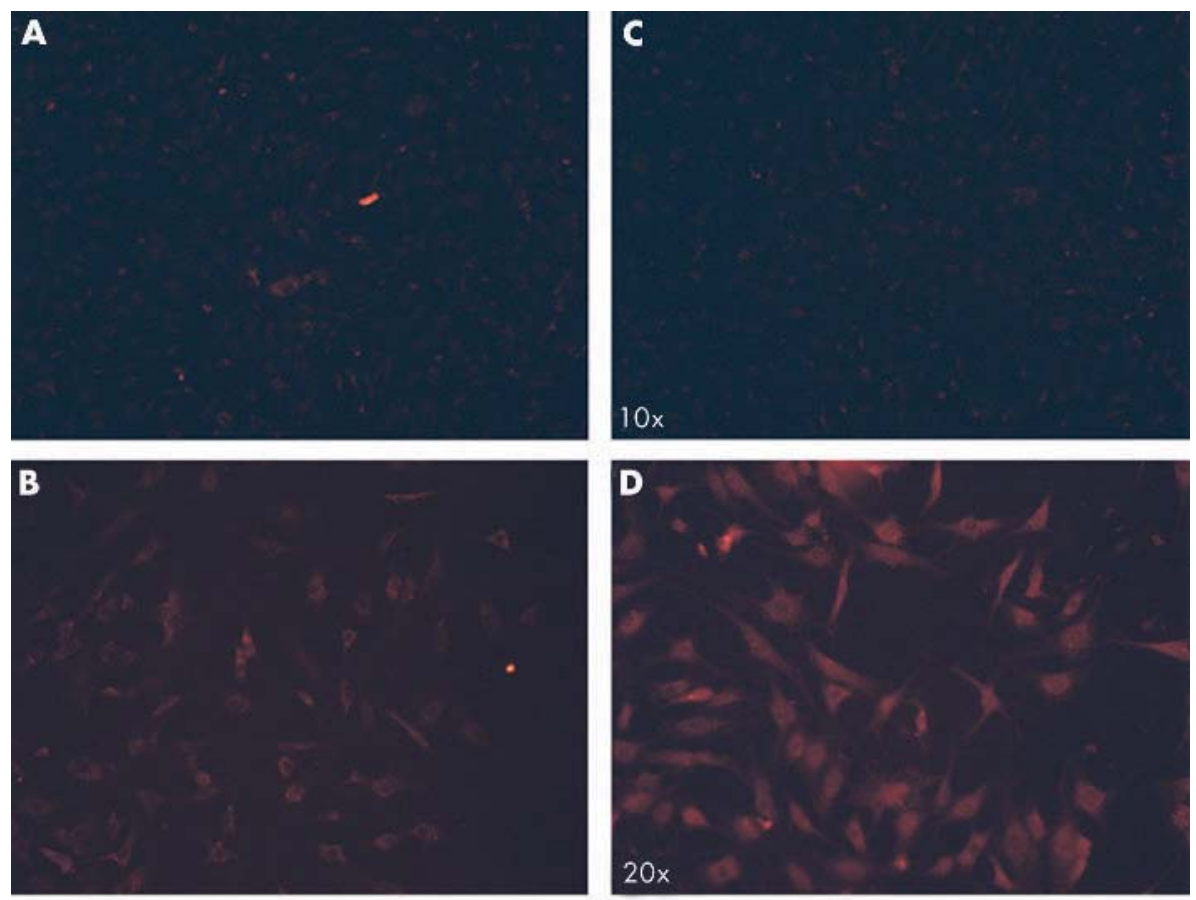

$\mathbf{E}$

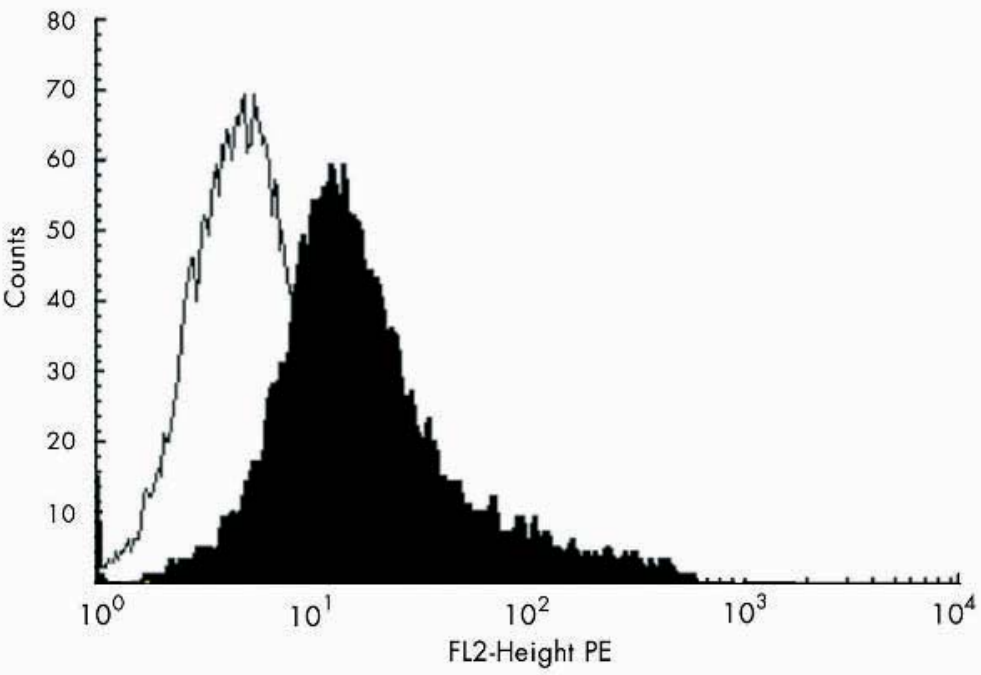

Figure 4 Immunofluorescence and flow cytometry detection of galectin-3 in OA chondrocytes. Cells were incubated with a specific anti-galectin-3 polyclonal antibody $(B, D)$ or non-immune-serum $(A, C)$ and detected with a fluorescent conjugated secondary antibody. $(A, B)$ non-permeabilised cells; (C, D) permeabilised cells; (E) cell surface expression of galectin-3 by primary OA articular chondrocytes. Non-permeabilised cells were immunostained with a polyclonal anti-galectin-3 (filled histogram) or with non-immune serum (open histogram) followed by phycoerythrin (PE) conjugated secondary antibody. The assessment that chondrocytes were not permeabilised was performed by using the 7-AAD dye, which penetrates into the cells, only when the membrane is disrupted. 


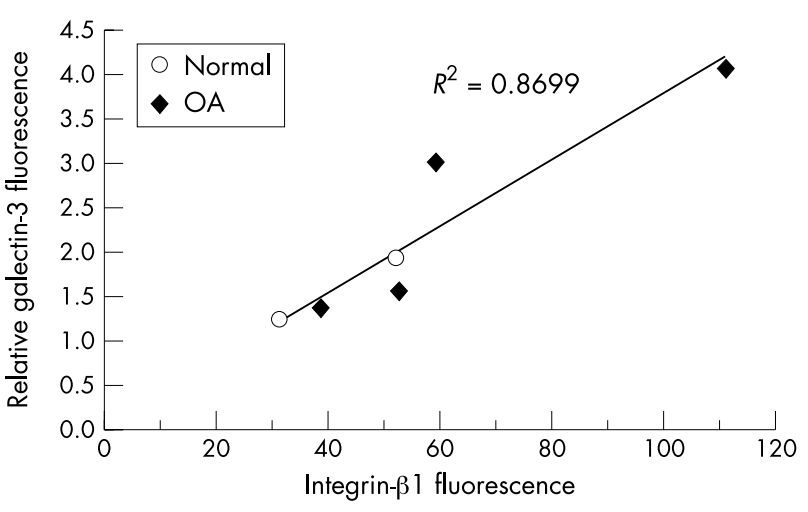

Figure 5 Correlation of galectin-3 presence with integrin- $\beta 1$ at the chondrocyte surface. Cell surface fluorescence was measured with either galectin-3 serum or integrin- $\beta 1$ antibody on non-permeabilised cells, as explained in "Materials and methods". As non-immune serum produced background level discrepancies, galectin-3 fluorescence was normalised to the non-immune signal. Relative galectin-3 fluorescence = galectin-3 fluorescence divided by non-immune fluorescence.

potential substrate for gelatinases A (MMP-2) and B (MMP9). Interestingly, this domain has a high degree of homology with the type II collagen $\alpha$ l chain..$^{53}$ Moreover, the amino acid site that might be recognised and cleaved by collagenase- 3 is positioned three amino acids before the cleavage site recognised by gelatinases. As we and others have previously shown that among the collagenase family collagenase-3 (MMP-13) had the highest activity on type II collagen, ${ }^{42}{ }^{43}$ we further investigated whether galectin-3 might be a substrate for collagenase-3. Hence, we performed in vitro proteolysis experiments in which human recombinant galectin-3 in solution was found either in monomer or multimer form, as described by Ochieng et al..$^{54}$ We found that collagenase- 3 cleaved galectin-3 whether the latter was present as a monomer or multimer (fig 6). In contrast, collagenase-1

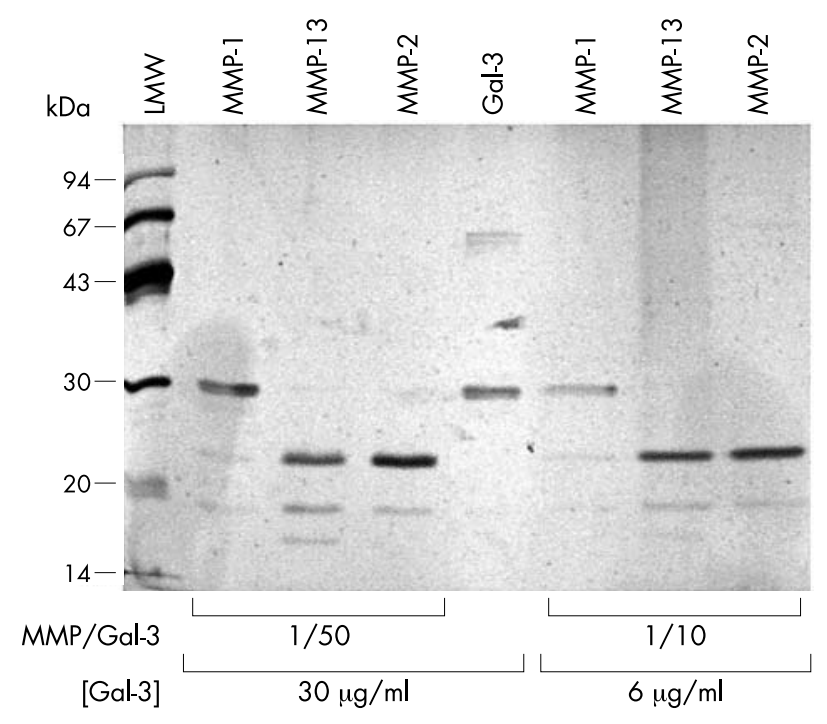

Figure 6 Proteolytic activity of collagenase-3 (MMP-13) on galectin-3. rh-galectin-3 was incubated in the presence of activated MMPs as described in "Materials and methods". As galectin-3 at high concentration could multimerise, ${ }^{26}$ two galectin-3 concentrations were used: $30 \mu \mathrm{g} / \mathrm{ml}$ (multimerisation) and $6 \mu \mathrm{g} / \mathrm{ml}$ (monomerisation). The reaction mixture was stopped with a solution of $6 \times$ Laemmli buffer, loaded onto an SDS-PAGE system, and the galectin- 3 was stained with silver nitrate. MMP-1, collagenase-1; MMP-13, collagenase-3; MMP-2, gelatinase A; Gal-3, galectin-3.

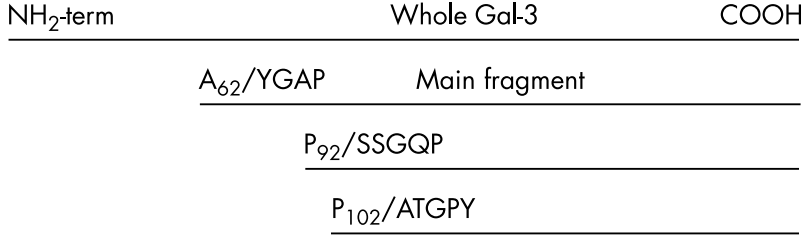

Figure 7 Schematic representation of galectin-3 sites generated by collagenase-3.

had very little activity on galectin-3. Gelatinase A was used as a positive control. Both the first and second fragments generated by collagenase- 3 and gelatinase A had a similar molecular weight, about 22 and $18 \mathrm{kDa}$, respectively. However, as the potential collagenase-3 cleavage site is similar to the one found in type II collagen and is localised three amino acids before the gelatinase site, the discrimination between these two cleavage sites was performed by sequencing the first fragment. To this end, experimental conditions were chosen where galectin-3 could multimerise, thereby favouring collagenase activity. Sequencing analysis demonstrated that collagenase- 3 cleaved galectin-3 at the identical site as the gelatinases (fig 7). Therefore, the main galectin-3 fragment from collagenase-3 was generated through its gelatinolytic activity.

\section{DISCUSSION}

Galectin-3 expression is strongly detected in pre- and hypertrophic chondrocytes before the signal is almost extinguished in late hypertrophic chondrocytes. ${ }^{28} 30$ Its localisation at this stage of bone development is only intracellular. Moreover, its function was associated with the coordination of cell death and vascular invasion. OA chondrocytes are often compared with hypertrophic-like chondrocytes because they express hypertrophic markers normally found in the developing bone. This phenomenon could be associated with an attempt at cartilage remodelling in order to counteract the resorption occurring during the pathological process. However, this remodelling is incomplete or seems to be impaired by a lack of different factors normally present in the developing bone. A complementary explanation of these events could also be tied to a differential localisation of some proteins, which would then modify the relationship between chondrocytes and their ECM.

In this study we showed that galectin-3 expression was increased in OA cartilage and that this protein was expressed at the surface of adult chondrocytes in culture. This new localisation may correlate with a metabolic state of chondrocytes where galectin-3 acts as an interface between the ECM and the cells. Indeed, although speculative, it is possible that galectin-3 competes for different ligands localised either at the chondrocyte surface or in the ECM, leading to chondrocyte adhesion. When expressed to the cell surface from different cell types, galectin-3 was identified as a cell adhesion protein for laminin, type IV collagen, fibronectin, elastin, and tenascins, ${ }^{10151655}$ and also as a receptor for advanced glycation end products. ${ }^{23}$

Among the potential ligands cited above, published data showed that advanced glycation end products were increased both in the aging process and OA cartilage ${ }^{24} 25$ and that OA chondrocytes produced more fibronectin, ${ }^{56}$ which might therefore be present in the ECM. In response to the increasing amount of fibronectin, chondrocytes synthesised $\alpha_{5} \beta_{1}$ integrin, the fibronectin receptor, to keep contact with the matrix. This is of importance, because adhesion regulates metabolic cell activity. Recently, Pulai et al showed that the chondrocyte survival signals were transmitted through the $\alpha_{5} \beta_{1}$ integrin, ${ }^{22}$ while Kurtis et al demonstrated that this 
integrin was implicated in chondrocyte adhesion. ${ }^{57}$ This latter group also showed that blocking $\beta_{1}$ integrin subunits appeared to inhibit chondrocyte adhesion slightly more than did blocking of $\alpha_{5} \beta_{1}$ integrin, indicating that other integrins containing the $\beta_{1}$ subunit may be involved in chondrocyte adhesion to cartilage. Chondrocytes can also produce other integrins, such as $\alpha_{1} \beta_{1}, \alpha_{3} \beta_{3}, \alpha_{6} \beta_{1}, \alpha_{v} \beta_{3}$, and $\alpha_{v} \beta_{5}{ }^{58}$ but the $\alpha_{1}$ and the $\beta_{1}$ integrin subunits are increased in $\mathrm{OA}^{, 51}$ and in our study we have shown a strong correlation between galectin-3 and integrin- $\beta 1$ at the chondrocyte surface. Furthermore, it was recently shown that the $\alpha_{1} \beta_{1}$ integrin was a preferential receptor for type VI collagen, ${ }^{58}$ the synthesis of which is increased in OA. Interestingly, Ochieng et al showed that both $\alpha_{1}$ integrin, and $\beta_{1}$ integrin were ligands for galectin-3. ${ }^{15}$ Therefore, $\beta_{1}$ integrins may be targeted by galectin- 3 during the OA process. Hence, the new localisation of galectin-3 in OA chondrocytes might play a part in the regulation of adhesive molecules towards the ECM. In fact, galectin-3 might interact with several ligands present either in the ECM or at the cell surface, and the affinity of galectin-3 for these ligands would lead to a regulation in the adhesion of chondrocytes and modification of internal signals. Parenthetically, although our number of specimens is low, it seems that macroscopic normal cartilage could contain some chondrocytes expressing a high level of integrin- $\beta 1$ at their surface, suggesting the beginning of the modification in the interaction of chondrocytes and their matrix.

Another point of regulation in the adhesiveness mediated by galectin-3 is the susceptibility of its N-terminal domain to cleavage by MMPs, in particular by MMP-2 and MMP-9. ${ }^{26}$ The N-terminal domain allows galectin-3 multimerisation, but when this domain is cleaved, galectin-3 can no longer bridge two cells or a cell and the nearest ECM. Moreover, this proteolysis induces a modification in the affinity of galectin-3 for its ligands. As the N-terminal domain of galectin-3 was previously shown to share a high degree of homology with the type II collagen $\alpha$ l chain, we investigated the collagenase3 activity toward galectin-3. Indeed, collagenase- 3 is the enzyme that has the highest activity on type II collagen among the members of the collagenase family. Our in vitro data showed that collagenase-3 cleaved galectin-3 at the identical site previously shown for MMP-2 and MMP-9 by others, indicating that the multimerisation of the $\mathrm{N}$-terminal domain of galectin-3 did not re-create a triple helix as in the case of collagens. Therefore, the gelatinolytic activity of collagenase- 3 was essential. This finding was interesting and might explain why collagenase- 1 had almost no activity on galectin-3, because the gelatinolytic activity of collagenase-1 is 44 -fold weaker than that of collagenase-3. ${ }^{59}$ Moreover, collagenase- 3 is increased during OA, particularly in the deep layer of the cartilage. ${ }^{42}{ }^{60}$ Therefore, it can be suggested that galectin-3 and collagenase-3 might be involved in a coordinate process during cartilage remodelling.

In summary, this study showed that galectin-3 synthesis was increased in OA chondrocytes, and its localisation at the chondrocyte surface indicated a new function for these cells. Indeed, this study raises the hypothesis that galectin-3, when binding to different adhesive molecules and being cleaved by MMPs, may balance the adhesiveness of chondrocytes and this, more particularly, during the OA process.

\section{ACKNOWLEDGEMENTS}

The authors thank Heather Yampolsky and Lorraine Doré for their assistance in the preparation of this manuscript, and Drs Jean-Luc Senécal, Yves Raymond, and Mélanie Dieudé for flow cytometry experiments and helpful discussions (CR-CHUM, Notre Dame Hospital). Confocal microscopy was performed with the collaboration of Drs Robert Nabi and Mohammad Amraei from the Department of Pathology and Cell Biology (University of Montreal).
This study was supported in part by grant TAS 01/0033 (PR) from the Canadian Arthritis Society and by the Centre de Recherche du CHUM (PR). Pascal Reboul is a recipient of a Dr André Lanthier Scholarship from the University of Montreal.

\section{Authors' affiliations}

M Guévremont, J Martel-Pelletier, C Boileau, J-C Fernandes, J-P Pelletier, P Reboul, Unité de Recherche en Arthrose, Centre de

Recherche du Centre Hospitalier de l'Université de Montréal, Montréal, Québec, Canada

F-T Liv, Department of Dermatology, Sacramento, University of California-Davis, California, USA

M Richard, Département de Biochimie, Faculté de Médecine Lyon-Sud, Lyon, France

\section{REFERENCES}

1 Dean DD, Martel-Pelletier J, Pelletier JP, Howell DS, Woessner JF Jr. Evidence for metalloproteinase and metalloproteinase inhibitor imbalance in human osteoarthritic cartilage. J Clin Invest 1989;84:678-85.

2 Poole AR. Cartilage in health and disease. In: Koopman WJ, ed. Arthritis and allied conditions: a textbook of rheumatology. Baltimore: Williams \& Wilkins, 1997:255-308.

3 Campbell CJ. The healing of cartilage defects. Clin Orthop 1969;64:45-63.

$4 \mathrm{Kim}$ HK, Moran ME, Salter RB. The potential for regeneration of articular cartilage in defects created by chondral shaving and subchondral abrasion. An experimental investigation in rabbits. J Bone Joint Surg Am 1991;73:1301-15.

5 Barondes SH. Bifunctional properties of lectins: lectins redefined. Trends Biochem Sci 1988;13:480-2.

6 Raimond J, Zimonjic DB, Mignon C, Mattei M, Popescu NC, Monsigny M, et al. Mapping of the galectin-3 gene (LGALS3) to human chromosome 14 at region 14q21-22. Mamm Genome 1997;8:706-7.

7 Kadrofske MM, Openo KP, Wang JL. The human LGALS3 (galectin-3) gene: determination of the gene structure and functional characterization of the promoter. Arch Biochem Biophys 1998;349:7-20.

8 van den Brule FA, Fernandez PL, Buicu C, Liu FT, Jackers P, Lambotte R, et al. Differential expression of galectin-1 and galectin-3 during first trimester human embryogenesis. Dev Dyn 1997;209:399-405.

9 Dagher SF, Wang JL, Patterson RJ. Identification of galectin-3 as a factor in pre-mRNA splicing. Proc Natl Acad Sci USA 1995;92:1213-17.

10 Bao Q, Hughes RC. Galectin-3 expression and effects on cyst enlargement and tubulogenesis in kidney epithelial MDCK cells cultured in threedimensional matrices in vitro. J Cell Sci 1995; 108(Pt 8):2791-800

11 Yang RY, Hsu DK, Liu FT. Expression of galectin-3 modulates T-cell growth and apoptosis. Proc Natl Acad Sci USA 1996;93:6737-42.

$12 \mathrm{Kim}$ HR, Lin HM, Biliran H, Raz A. Cell cycle arrest and inhibition of anoikis by galectin-3 in human breast epithelial cells. Cancer Res 1999;59:4148-54.

13 Akahani S, Nangia-Makker P, Inohara H, Kim HR, Raz A. Galectin-3: a novel antiapoptotic molecule with a functional BHI (NWGR) domain of Bcl-2 family. Cancer Res 1997; 57:5272-6.

14 van den Brule FA, Buicu C, Sobel ME, Liu FT, Castronovo V. Galectin-3, a laminin binding protein, fails to modulate adhesion of human melanoma cells to laminin. Neoplasma 1995;42:215-19.

15 Ochieng J, Leite-Browning ML, Warfield P. Regulation of cellular adhesion to extracellular matrix proteins by galectin-3. Biochem Biophys Res Commun 1998;246:788-91

16 Ochieng J, Warfield P, Green-Jarvis B, Fentie I. Galectin-3 regulates the adhesive interaction between breast carcinoma cells and elastin. J Cell Biochem 1999;75:505-14.

17 Ochieng J, Green B, Evans S, James O, Warfield P. Modulation of the biological functions of galectin-3 by matrix metalloproteinases. Biochim Biophys Acta 1998;1379:97-106.

18 Dong S, Hughes RC. Macrophage surface glycoproteins binding to galectin-3 (Mac-2-antigen). Glycoconj J 1997; 14:267-74.

19 Frigeri LG, Zuberi RI, Liu FT. Epsilon BP, a beta-galactoside-binding animal lectin, recognizes lgE receptor ( $\mathrm{Fc}$ epsilon $\mathrm{RI}$ ) and activates mast cells. Biochemistry 1993;32:7644-9.

20 Sato S, Hughes RC. Binding specificity of a baby hamster kidney lectin for $\mathrm{H}$ type I and II chains, polylactosamine glycans, and appropriately glycosylated forms of laminin and fibronectin. J Biol Chem 1992;267:6983-90.

21 Piperno M, Reboul P, Hellio le Graverand MP, Peschard M, Annefeld M, Richard $M$, et al. Osteoarthritic cartilage fibrillation is associated with a decrease in chondrocyte adhesion to fibronectin. Osteoarthritis Cartilage 1998;6:393-9.

22 Pulai Jl, Del Carlo M Jr, Loeser RF. The alpha5betal integrin provides matrix survival signals for normal and osteoarthritic human articular chondrocytes in vitro. Arthritis Rheum 2002;46:1528-35.

23 Vlassara H, Li YM, Imani F, Wojciechowicz D, Yang Z, Liu FT, et al. Identification of galectin-3 as a high-affinity binding protein for advanced glycation end products (AGE): a new member of the AGE-receptor complex. Mol Med 1995; 1:634-46.

24 Nerlich AG, Schleicher ED, Boos N. 1997 Volvo Award winner in basic science studies. Immunohistologic markers for age-related changes of human lumbar intervertebral discs. Spine 1997;22:2781-95.

25 Verzijl N, DeGroot J, Ben ZC, Brau-Benjamin O, Maroudas A, Bank RA, et al. Crosslinking by advanced glycation end products increases the stiffness of the 
collagen network in human articular cartilage: a possible mechanism through which age is a risk factor for osteoarthritis. Arthritis Rheum 2002;46:114-23.

26 Ochieng J, Fridman R, Nangia-Makker P, Kleiner DE, Liotta LA, StetlerStevenson WG, et al. Galectin-3 is a novel substrate for human matrix metalloproteinases-2 and -9. Biochemistry 1994;33:14109-14.

27 Aubin JE, Liu F, Malaval L, Gupta AK. Osteoblast and chondroblast differentiation. Bone 1995;17:77-83S.

28 Colnot C, Sidhu SS, Poirier F, Balmain N. Cellular and subcellular distribution of galectin-3 in the epiphyseal cartilage and bone of fetal and neonatal mice. Cell Mol Biol (Noisy-le-grand) 1999;45:1191-202.

29 Fowlis D, Colnot C, Ripoche MA, Poirier F. Galectin-3 is expressed in the notochord, developing bones, and skin of the postimplantation mouse embryo. Dev Dyn 1995;203:241-51.

30 Nurminskaya $M$, Linsenmayer TF. Identification and characterization of upregulated genes during chondrocyte hypertrophy. Dev Dyn 1996;206:260-71.

31 Colnot C, Sidhu SS, Balmain N, Poirier F. Uncoupling of chondrocyte death and vascular invasion in mouse galectin 3 null mutant bones. Dev Biol $2001 ; 229: 203-14$.

32 Altman RD, Asch E, Bloch DA, Bole G, Borenstein D, Brandt KD, et al. Development of criteria for the classification and reporting of osteoarthritis. Classification of osteoarthritis of the knee. Arthritis Rheum 1986;29:1039-49.

33 Reboul P, Pelletier JP, Tardif G, Benderdour M, Ranger P, Bottaro DP, et al. Hepatocyte growth factor induction of collagenase 3 production in human osteoarthritic cartilage: involvement of the stress-activated protein kinase/cJun $\mathrm{N}$-terminal kinase pathway and a sensitive p38 mitogen-activated protein kinase inhibitor cascade. Arthritis Rheum 2001;44:73-84.

34 Pelletier JP, Lascau-Coman V, Jovanovic D, Fernandes JC, Manning P, Currie $M G$, et al. Selective inhibition of inducible nitric oxide synthase in experimental osteoarthritis is associated with reduction in tissue levels of catabolic factors. J Rheumatol 1999;26:2002-14.

35 Moldovan F, Pelletier JP, Hambor J, Cloutier JM, Martel-Pelletier J. Collagenase-3 (matrix metalloprotease 13) is preferentially localized in the deep layer of human arthritic cartilage in situ: In vitro mimicking effect by transforming growth factor beta. Arthritis Rheum 1997;40:1653-61.

36 Boileau C, Martel-Pelletier J, Moldovan F, Jouzeau JY, Netter P, Manning PT, et al. The in situ up-regulation of chondrocyte interleukin-1-converting enzyme and interleukin-18 levels in experimental osteoarthritis is mediated by nitric oxide. Arthritis Rheum 2002;46:2637-47.

37 Tardif G, Di Battista JA, Pelletier J-P, Martel-Pelletier J. Measurement of interleukin mRNA by Northern botting using a non-radioactive detection method. In: O'Neill L, ed. Interleukin protocols. Totowa, New Jersey, USA: Humana Press Inc, 2000

38 Smith PK, Krohn RI, Hermanson GT, Mallia AK, Gartner FH, Provenzano MD et al. Measurement of protein using bicinchoninic Acid. Anal Biochem 1985; 150:76-85.

39 Hsu DK, Zuberi RI, Liu FT. Biochemical and biophysical characterization of human recombinant lgE-binding protein, an S-type animal lectin. J Biol Chem 1992;267:14167-74.

40 Kirsch T, Swoboda B, Nah H. Activation of annexin II and V expression, terminal differentiation, mineralization and apoptosis in human osteoarthritic cartilage. Osteoarthritis Cartilage 2000;8:294-302.

41 Mollenhaver J, Mok MT, King KB, Gupta M, Chubinskaya S, Koepp H, et al Expression of anchorin Cll (cartilage annexin V) in human young, normal adult, and osteoarthritic cartilage. J Histochem Cytochem 1999;47:209-20.

42 Reboul P, Pelletier JP, Tardif G, Cloutier JM, Martel-Pelletier J. The new collagenase, collagenase- 3 , is expressed and synthesized by human chondrocytes but not by synoviocytes: a role in osteoarthritis. J Clin Invest 1996;97:2011-19.

43 Mitchell PG, Magna HA, Reeves LM, Lopresti-Morrow LL, Yocum SA, Rosner PJ, et al. Cloning, expression, and type II collagenolytic activity of matrix metalloproteinase-13 from human osteoarthritic cartilage. J Clin Invest 1996;97:761-8.

44 Pullig O, Weseloh G, Gauer S, Swoboda B. Osteopontin is expressed by adult human osteoarthritic chondrocytes: protein and mRNA analysis of normal and osteoarthritic cartilage. Matrix Biol 2000;19:245-55.

45 von der Mark K, Kirsch T, Nerlich A, Kuss A, Weseloh G, Gluckert K, et al. Type $X$ collagen synthesis in human osteoarthritic cartilage. Indication of chondrocyte hypertrophy. Arthritis Rheum 1992;35:806-11.

46 Sato S, Hughes RC. Control of Mac-2 surface expression on murine macrophage cell lines. Eur J Immunol 1994;24:216-21.

47 Wang L, Inohara H, Pienta KJ, Raz A. Galectin-3 is a nuclear matrix protein which binds RNA. Biochem Biophys Res Commun 1995;217:292-303.

48 Hubert M, Wang SY, Wang JL, Seve AP, Hubert J. Intranuclear distribution of galectin-3 in mouse 3 T3 fibroblasts: comparative analyses by immunofluorescence and immunoelectron microscopy. Exp Cell Res 1995:220:397-406.

49 Craig SS, Krishnaswamy P, Irani AM, Kepley CL, Liu FT, Schwartz LB. Immunoelectron microscopic localization of galectin-3, an lgE binding protein, in human mast cells and basophils. Anat Rec 1995;242:211-19.

50 Moutsatsos IK, Davis JM, Wang JL. Endogenous lectins from cultured cells: subcellular localization of carbohydrate-binding protein 35 in 3 T3 fibroblasts. J Cell Biol 1986; 102:477-83.

51 Loeser RF, Carlson CS, McGee MP. Expression of beta 1 integrins by cultured articular chondrocytes and in osteoarthritic cartilage. Exp Cell Res 1995;217:248-57.

52 Enomoto M, Leboy PS, Menko AS, Boettiger D. Beta 1 integrins mediate chondrocyte interaction with type I collagen, type II collagen, and fibronectin Exp Cell Res 1993;205:276-85.

53 Raz A, Pazerini G, Carmi P. Identification of the metastasis-associated galactoside-binding lectin as a chimeric gene product with homology to an lgE-binding protein. Cancer Res 1989;49:3489-93

54 Ochieng J, Platt D, Tait L, Hogan V, Raz T, Carmi P, et al. Structure-function relationship of a recombinant human galactoside-binding protein. Biochemistry 1993;32:4455-60.

55 Probstmeier R, Montag D, Schachner M. Galectin-3, a beta-galactosidebinding animal lectin, binds to neural recognition molecules. J Neurochem 1995;64:2465-72.

56 Burton-Wurster N, Butler M, Harter S, Colombo C, Quintavalla J, Swartzendurber $D$, et al. Presence of fibronectin in articular cartilage in two animal models of osteoarthritis. J Rheumatol 1986;13:175-82.

57 Kurtis MS, Schmidt TA, Bugbee WD, Loeser RF, Sah RL. Integrin-mediated adhesion of human articular chondrocytes to cartilage. Arthritis Rheum 2003:48:110-18.

58 Loeser RF, Sadiev S, Tan L, Goldring MB. Integrin expression by primary and immortalized human chondrocytes: evidence of a differential role for alphalbetal and alpha2betal integrins in mediating chondrocyte adhesion to types II and VI collagen. Osteoarthritis Cartilage 2000;8:96-105.

59 Knauper V, Lopez-Otin C, Smith B, Knight G, Murphy G. Biochemical characterization of human collagenase-3. J Biol Chem 1996;271:1544-50.

60 Dahlberg L, Billinghurst RC, Manner P, Nelson F, Webb G, lonescu M, et al. Selective enhancement of collagenase-mediated cleavage of resident type II collagen in cultured osteoarthritic cartilage and arrest with a synthetic inhibitor that spares collagenase 1 (matrix metalloproteinase 1). Arthritis Rheum 2000;43:673-82 